\title{
A mesclagem conceptual e a construção morfológica na interpretação do poema cidade/city/cité, de Augusto de Campos
}

\author{
Conceptual blending and morphological construction in the \\ interpretation of Augusto de Campos's poem cidade/city/cité
}

Henrique Alvarenga Cosenza*

henriquecosenza@gmail.com

Universidade Federal de Minas Gerais

RESUMO: Este trabalho, que é parte de dissertação defendida em 2019, na Fale/UFMG, apresenta a analise do poema cidade/city/cité, de Augusto de Campos, buscando demonstrar como o ferramental teórico da Linguística Cognitiva se presta a descrever processos necessários à interpretação dos mais variados tipos de produção linguística, incluindo a poética. Assim, o estudo se encaixa na linha de investigação da poética cognitiva. O poema é composto de um único neologismo que pode ser decomposto em vinte e oito palavras, que formam inputs numa rede de mesclagem conceptual. $O$ mapeamento entre os inputs revela uma estrutura abstrata a ser projetada no espaço genérico dessa rede. Essa estrutura abstrata indica a existência de uma construção morfológica do Português. O estudo, portanto, atinge o objetivo de demonstrar a aplicabilidade do referencial teórico adotado na descrição de processos demandados na interpretação do tipo de texto analisado, bem como corrobora premissas da gramática de construções e indica a existência de uma construção morfológica na língua portuguesa.

PALAVRAS-CHAVE: Construção morfológica. Mesclagem. Poética cognitiva.

ABSTRACT: This paper, which is part of my master's thesis defended in 2019, presents the analysis of the cidade/city/cité poem, by Augusto de Campos, seeking to demonstrate how the theoretical tools of Cognitive Linguistics lends itself to describing the necessary processes for the interpretation of the most varied types of linguistic production, including poetics. Thus, the study fits the line of investigation of cognitive poetics. The poem is composed of a single neologism that can be broken down into twenty eight words, each of which forms inputs into a conceptual blending network. The mapping between inputs reveals an abstract structure to be projected into the generic space of this network. This abstract structure indicates the existence of a morphological construction of Portuguese. The study, therefore, achieves the objective of demonstrating the applicability of the theoretical framework adopted in the description of processes required in the interpretation of the type of text analyzed, as well as corroborating premises of the grammar of constructions and indicates the existence of a morphological construction in the Portuguese language.

KEYWORDS: Construction morphology. Blending. Cognitive poetics.

\footnotetext{
* Mestre em Estudos Linguísticos pelo Programa de Pós-Graduação em Estudos Linguísticos (PosLin) da Universidade Federal de Minas Gerais (UFMG)
} 


\section{Considerações iniciais}

Este artigo é parte de dissertação defendida em 2019, na Fale/UFMG, e busca demonstrar a aplicabilidade do arcabouço teórico da Linguística Cognitiva na descrição de processos demandados para interpretação dos mais diversos tipos de produção linguística, incluindo a produção criativa com fins estéticos. Mais especificamente, buscou-se demonstrar como a mesclagem conceptual e a gramática de construções, em especial a construção morfológica, podem descrever processos demandados na interpretação do poema cidade/city/cité, de Augusto de Campos (2000). Devido à sua proposta quanto ao objeto de estudo e ao referencial teórico adotado, o estudo também pode ser caracterizado como alinhado às investigações em poética cognitiva, uma vez que essa linha de pesquisa tem como objeto textos literários e busca identificar processos cognitivos concernentes, em especial, à interpretação desses textos (FREEMAN, 2007; STOCKWELL, 2002; VANDAELE, J.; BRÔNE, 2009). Dessa forma, a Poética Cognitiva se utiliza do arcabouço teórico das ciências cognitivas, para escrutinar como o leitor do texto literário processa sua interpretação, identificando quais processos cognitivos possibilitam a compreensão textual.

Esta investigação tem como intuito corroborar a premissa da gramática de construções de que não há distinção entre sintaxe e léxico, e que a formação de palavras difere de estruturas maiores apenas em sua complexidade interna. Este quadro teórico propõe que as construções são as unidades linguísticas básicas e que são essas unidades que o falante conhece e manipula. Assim, pretendeu-se, neste estudo, descrever como esse conhecimento é utilizado pelo falante na interpretação de textos poéticos. Além disso, buscou-se demonstrar que "a linguagem poética usa os mesmos aparatos conceptuais e linguísticos que a linguagem ordinária" (LAKOFF; TURNER apud FREEMAN, 2007, p. 1185) ${ }^{1}$ ao trazer proposições teóricas da Linguística Cognitiva na análise de um poema, que é característico dos estudos em poética cognitiva.

O poema analisado é composto por um único neologismo que, para ser interpretado, demanda do leitor a identificação das palavras que o compõem. 0

\footnotetext{
${ }^{1}$ Todas as citações em língua estrangeira do trabalho serão apresentadas e traduzidas pelo autor do trabalho no corpo do texto, para maior fluidez da leitura, sendo apresentado o texto original nas notas de rodapé. No original: "Poetic language uses the same conceptual and linguistic apparatus as ordinary language".
} 
poema foi entendido como um único neologismo devido, primeiramente, a sua apresentação gráfica, em uma linha, sem espaçamentos, tal como as palavras são costumeiramente escritas. Além disso, em sua interpretação, foram identificadas vinte oito palavras dicionarizadas do Português formadoras desse único termo que compõe o poema, permitindo, portanto, considerá-lo um neologismo composto de várias palavras dicionarizadas. A identificação das palavras utilizadas no neologismo permite que se identifiquem suas estruturas comuns que, consequentemente, permitem a compreensão do texto poético. Entendemos que, ainda que não reflitam a totalidade dos fenômenos envolvidos na interpretação do poema, as proposições teóricas da Linguística Cognitiva de mesclagem conceptual e construção morfológica descrevem satisfatoriamente processos subjacentes necessários à interpretação do poema analisado no presente estudo.

O primeiro passo para a análise dos dados foi a interpretação do texto do poema, como dito, composto por um neologismo que era passível de decomposição em outras palavras. A interpretação do texto indicava que o autor do poema tentava caracterizar o que é uma cidade e as características que ele associa a ela estão explicitadas nas palavras que compõem o neologismo. O segundo passo foi a identificação dessas palavras formadoras do neologismo. Em seguida, a partir da verificação no dicionário Houaiss (2009), determinou-se quais as bases formadoras das palavras, bem como suas classificações. Ou seja, ao identificar, no poema, uma palavra como, por exemplo, atrocidade, em que o dicionário identifica como tendo um de seus significados "qualidade do que é atroz"; e outra palavra como mendicidade, definida como "estado, condição de quem mendiga" e "ato ou efeito de mendigar", buscamos a classificação tradicional dos termos encontrados na definição do dicionário que servem de base na união com o sufixo -idade, nos exemplos, atroz e mendigar, adjetivo e verbo, respectivamente. A partir disso, foi analisado se havia regularidade nas classificações das palavras-base e se os produtos da união dessas com o sufixo apresentavam propriedades semânticas constantes, visando à proposição de uma construção morfológica.

No que tange à morfologia, os dados foram analisados de acordo com a forma utilizada por Booij (2013), para quem se apresenta a configuração formal da palavra de um lado, na forma [ $X$-sufixo], em que $X$ se refere à base utilizada na composição da palavra, e, de outro lado, a especificação semântica, na forma [W SEM], em que $W$ exprime o que o sufixo determina e SEM se refere à semântica 
relativa a $X$ que se manifesta na produção da palavra. As palavras que compõem o neologismo se caracterizam pelo uso do sufixo -idade na formação de substantivos abstratos. Buscou-se pesquisar se as palavras encontradas contêm traços de um pareamento de forma e significado em suas manifestações, definindo, portanto, uma construção. A opção pelo uso do sufixo -idade, ao invés de -dade, tradicionalmente referido nas gramáticas normativas, se sustenta na pesquisa de Pezzati (1990), que demonstra que em $96,5 \%$ das ocorrências deste sufixo se dão com a presença de /i/, sendo esta, portanto, sua forma prototípica.

Dessa forma, concluímos que, no processo de interpretação do poema, o leitor deve ser capaz de identificar as palavras formadoras do neologismo, que servirão de inputs numa rede de mesclagem conceptual. Os mapeamentos entre inputs apresentam uma estrutura abstrata comum que será projetada no espaço genérico da rede e essa estrutura abstrata é uma construção morfológica. No espaço mescla, ocorre a estrutura emergente que é o substantivo cidade, sendo este qualificado de acordo com a semântica das bases formadoras das palavras dos inputs.

Este artigo está dividido em duas seções. Na primeira, uma breve apresentação dos conceitos teóricos utilizados, constando os precursores e as premissas teóricas da mesclagem conceptual e da gramática de construções e, mais especificamente, as construções morfológicas. Na segunda seção, os dados e a análise são apresentados.

\section{Referencial teórico}

\subsection{Espaços mentais e mesclagem conceptual}

A teoria dos espaços mentais foi proposta por Fauconnier e surge como uma alternativa cognitivista para solução de problemas semânticos de línguas naturais de que as teorias baseadas em lógica formal não davam conta (LAKOFF; SWEETSER, 1994, p. xi). Assim, uma sentença como João quer comprar uma cafeteira, em uma análise de condições de verdade, é problemática, uma vez que, por se tratar de um desejo da pessoa de quem se fala, não há como verificar a referência no mundo diretamente, como seria possível em uma afirmação como João tem uma cafeteira. A tentativa de solucionar esse tipo questão nas abordagens formais foi a de que haveria o mundo objetivo, real, e mundos possíveis, identificados com as crenças, 
desejos e outras posturas de uma pessoa. No entanto, se eles existem, onde estariam? Fauconnier então substitui a noção de mundos possíveis pela de espaços mentais, argumentando sua existência no aparato cognitivo humano (CROFT; CRUSE, 2004, p. 33). De acordo com Fauconnier e Turner (2006, p. 307), os espaços mentais são estruturas conceptuais que têm o propósito de compreensão de eventos locais e planejamento de ação e que surgem nos momentos de fala e pensamento, transformando-se ao longo da dinâmica desses.

Segundo a teoria, uma expressão como João tem uma cafeteira é compreendida num espaço referente à realidade presente, ou realidade comum reconhecida entre os falantes, chamada de espaço base. Esse espaço conterá elementos eliciados pelas pistas linguísticas; dessa forma, no exemplo acima apresentado, o espaço contém João e a cafeteira, e é estruturado de acordo com a relação de posse de um pelo o outro, conforme a figura abaixo:

\section{Figura 1}

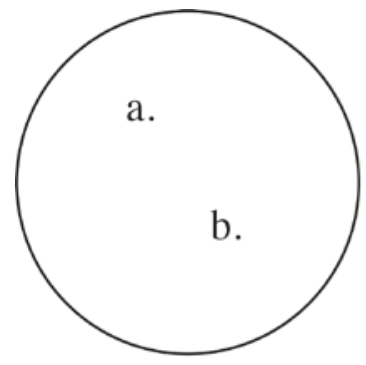
a. João
b. cafeteira
a ter b

Fonte: Adaptado de Fauconnier (2007, p. 357)

Assim, o espaço mental apresentado, representado pelo círculo na figura acima, se refere ao tempo presente e contém elementos do discurso. Este espaço é estruturado por um frame, o retângulo na figura acima, em que os elementos eliciados são apresentados, bem como a relação entre eles. O espaço mental é, portanto, como um domínio conceptual em que ocorrem representações parciais, uma vez que são esquemáticas, não contendo todas as características da realidade ou dos elementos nele representados. No entanto, eles podem ser enriquecidos. Por exemplo, se, após a afirmação da posse da cafeteira por João, o falante disser Ela é vermelha, o ouvinte é capaz de associar essa característica ao elemento no espaço mental. 
Nas dinâmicas do pensamento ou da fala, espaços mentais são construídos e interligados por diversos tipos de mapeamento entre si, em especial os de identidade e analogia (FAUCONNIER, 2007 p. 351). Assim, suponhamos que, após as afirmações de João ter uma cafeteira e ela ser vermelha, o falante diga que Há dois anos, ela era azul. A partir dessa expressão, um novo espaço mental, referente ao tempo passado, é criado, e ocorre um mapeamento de elementos do espaço base para este espaço.

Desse modo, no desenrolar discursivo, os espaços mentais são construídos e interligados em uma rede e, em qualquer momento, "um desses espaços é a base para o sistema, e um dos espaços (possivelmente o mesmo) está no foco" (FAUCONNIER, 1997, p. 38; itálicos do original). ${ }^{2}$ O espaço base está sempre disponível para que se criem novos espaços a ele conectados e, ao longo da interação discursiva, o participante muda o foco de um para outro dos espaços da rede. No nosso exemplo, a base é o tempo presente, em que João possui uma cafeteira vermelha, e o foco é o tempo passado, em que a cafeteira é azul. Os novos espaços mentais da rede são gerados pelos construtores de espaços mentais, que são estruturas linguísticas que demandam a criação de um novo espaço ou mudam a atenção de um para outro espaço previamente criado (EVANS; GREEN, 2006, p. 371).

Essa proposta teórica é particularmente eficaz na descrição de como se processa o discurso narrativo, bem como para referências anafóricas, ambiguidades referenciais e estruturação de tempo e modo. No entanto, para nossos fins, ela se mostra importante por subsidiar outra proposição teórica advinda dessa abordagem de construção do significado, que é a mesclagem conceptual, conforme veremos a seguir.

\section{Mesclagem conceptual}

A proposta teórica da mesclagem conceptual foi apresentada por Fauconnier e Turner em 1993 (TURNER, 2007, p. 377), se caracterizando por ser uma operação cognitiva básica e responsável por muito da criatividade humana. Seus autores afirmam que esta operação cognitiva é decisiva no pensamento e ação humana, podendo ser identificada em uma grande diversidade de manifestações, e sendo

\footnotetext{
${ }^{2}$ No original: "one of the spaces is a base for the system, and one (possibly the same one) is in focus".
} 
responsável pelas origens das línguas, arte, religião, ciência (FAUCONNIER; TURNER, 2002, p. vi).

A mesclagem conceptual ocorre nas redes de espaços mentais, podendo ocorrer em qualquer ponto destas, e é um processo que possibilita a criação de novos significados. Para que ela ocorra, são necessários ao menos dois espaços de input com mapeamentos entre eles, que permitirão o estabelecimento de um espaço genérico, que, por sua vez, conterá elementos em comum mapeados dos inputs e, por fim, um espaço mescla, em que ocorrem projeções parciais dos elementos dos inputs e onde surge a estrutura emergente. O diagrama básico da mesclagem conceptual é a figura 2.

Figura 2

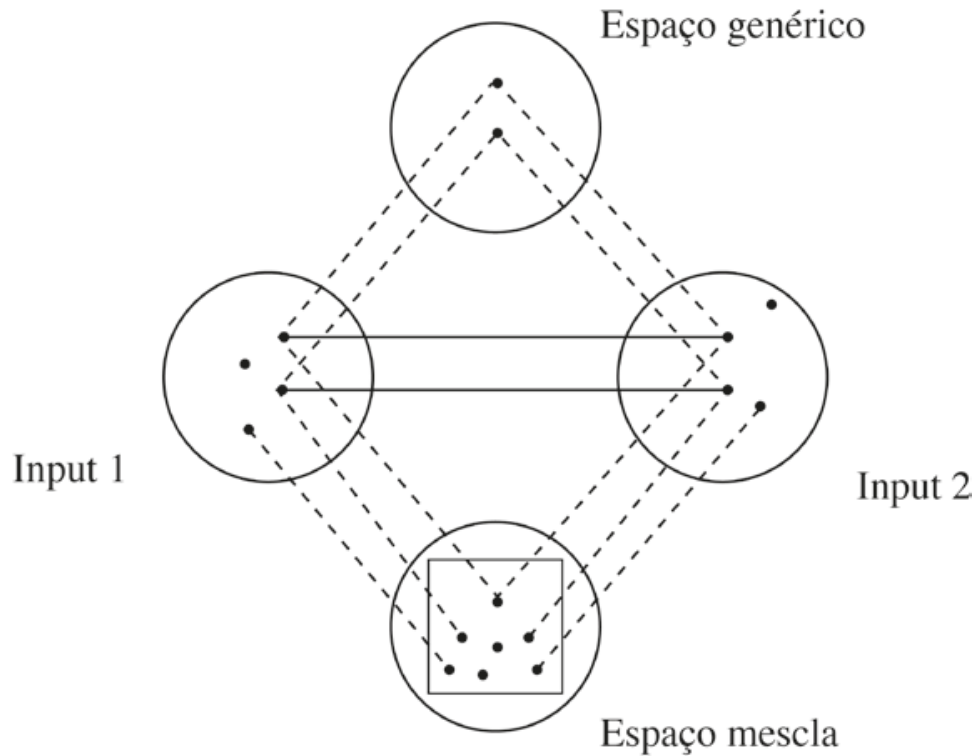

Fonte: Adaptado de Fauconnier e Turner (2002, p. 46)

No diagrama acima, os círculos alinhados horizontalmente são os espaços mentais de input e as linhas cheias representam os mapeamentos de elementos entre eles. Os círculos alinhados verticalmente são o espaço genérico, acima, e o espaço mescla, abaixo. As linhas pontilhadas indicam as conexões mapeadas entre esses espaços e os de input. No espaço mescla, há um retângulo que representa a estrutura emergente, que não advém diretamente dos inputs.

A mesclagem ocorre em três fases (FAUCONNIER; TURNER, 2002, P.6466): (i) A composição dos elementos encontrados nos inputs cria relações que não ocorreriam nos espaços distintos. (ii) O completamento traz estrutura adicional aos elementos no espaço mescla. (iii) A elaboração recruta a estrutura adicional do 
completamento e a elabora junto aos elementos presentes na mescla, integrandoos.

Para melhor compreender como se dá a operação da mesclagem conceptual, analisemos o exemplo encontrado em várias publicações dos autores, o enigma do monge budista, que recuperam de Koestler (1964, apud FAUCONNIER, 1997; FAUCONNIER; TURNER, 2002 e 2006):

Um monge budista começa, na madrugada de um dia, a subir uma montanha, alcança o topo ao pôr do sol, medita no topo por alguns dias até que, numa outra madrugada, começa a caminha para a base da montanha, que alcança no pôr do sol. Sem fazer suposições quanto ao seu início ou paradas, ou sobre o seu ritmo de seus passos durante a caminhada, prove que há um local no caminho que ele ocupa no mesmo horário do dia nas duas jornadas separadas. ${ }^{3}$

Segundo os autores, o passo inferencial necessário para a resolução do enigma seria imaginar o monge andando nas duas direções no mesmo dia, pois, assim, necessariamente haverá um local em que ele se encontra consigo na caminhada. Ainda que se solucione o enigma, essa operação mental de imaginar o mesmo monge andando em direções opostas no mesmo caminho ao mesmo tempo é, no mínimo, fantástica. No entanto, conseguimos fazer esse exercício imaginativo sem maiores dificuldades. Fauconnier e Turner afirmam que o que ocorre é uma mesclagem conceptual, que operaria conforme veremos.

Consoante com o diagrama acima, cada um dos círculos apresentados representa espaços mentais, como visto na seção anterior. No exemplo do monge, os espaços de input correspondem 1) à caminhada montanha acima e 2) à caminhada montanha abaixo.

Como dito anteriormente, a mesclagem conceptual necessita de, no mínimo, dois espaços de input; no entanto, pode ocorrer em uma rede mais ampla, não parecendo haver um limite prévio de espaços de input passíveis de participarem de uma mesclagem conceptual. Entre os espaços de input ocorrem mapeamentos de elementos contidos em cada um deles, em que um elemento de um input é identificado com sua contraparte no outro input. Assim, no exemplo, o caminhante

\footnotetext{
${ }^{3}$ No original: "A Buddhist monk begins at dawn one day walking up a mountain, reaches the top at sunset, meditates at the top for several days until one dawn when he begins to walk back to the foot of the mountain, which he reaches at sunset. Making no assumptions about his starting or stopping or about his pace during the trips, prove that there is a place on the path which he occupies at the same hour of the day on the two separate journeys".
} 
do input 1 tem como contraparte o caminhante no input 2, a direção da caminhada em 1 tem como contraparte a direção da caminhada em 2, e assim por diante.

Essas determinações de contrapartes entre os inputs gera o espaço genérico, que contém o que os inputs possuem em comum em qualquer momento do desenvolvimento da rede de mesclagem. No exemplo, teremos como elementos do espaço genérico, assim como nos inputs, apenas uma pessoa que se movimenta e sua posição, um caminho que liga a base da montanha ao topo, um dia de viagem. Não há especificação da direção do movimento ou do dia em questão (FAUCONNIER; TURNER, 2006, p. 308-309).

Os inputs também projetam em outro espaço, o espaço mescla. Nele, os caminhos de cada input se fundem, bem como os dois dias de caminhada, mas não se fundem os caminhantes de cada input, preservando, também, as diferentes posições dos caminhantes nos inputs, permitindo a imaginação do encontro entre os caminhantes. Assim, podemos notar que a projeção é seletiva e que alguns elementos se fundem, outros não e alguns nem participam da mesclagem, como, por exemplo, a data de cada caminhada dos inputs. O espaço mescla contém elementos que não estavam nos inputs, as estruturas emergentes. No exemplo, podemos verificar a ocorrência da composição, em que elementos dos inputs criam relações que não existiam em outros espaços da rede, como a existência de dois caminhantes, o direcionamento oposto das caminhadas, em que um começa do topo da montanha, outro da base, permitindo a comparação de suas posições ao longo do trajeto. Também podemos notar o completamento, que insere estrutura adicional à mescla. Fauconnier e Turner (2006, p. 310) afirmam que recuperamos, de experiências prévias, a imagem de duas pessoas começando, ao mesmo tempo, uma caminhada em polos opostos de um caminho e que esse conhecimento permite que saibamos que os caminhantes, em algum momento, se encontrarão no caminho. Assim, devido ao nosso conhecimento de mundo, essa estrutura emerge no espaço mescla, independentemente de ela existir em outros espaços da rede, via completamento.

Essa proposição teórica se mostra eficaz na descrição de processamentos cognitivos inconscientes que ocorrem em variadas produções linguísticas. Aliás, é a estrutura emergente que possibilita a compreensão de expressões como "O motorista é um barbeiro", em que apenas o mapeamento entre dois domínios (característico das metáforas), no caso, motorista e barbeiro, não permite a 
interpretação do primeiro como inábil para a função exercida. Assim, se faz necessária a emergência de algum elemento que embase essa interpretação, pois a mera identificação de contrapartes entre domínios não é suficiente para tal.

\subsection{Gramática de construções}

A gramática de construções surge no contexto em que a perspectiva gerativista dominava o cenário da pesquisa em Linguística, em que havia predomínio de uma ideia de composicionalidade na interpretação dos significados, que presume que o significado do todo seria a somatória de seus componentes. Desta forma, a abordagem deixava na periferia de suas investigações produções linguísticas interpretáveis por falantes de uma língua e que claramente não poderiam ser compreendidas via composição de suas unidades lexicais. Exemplos dessas produções vão desde expressões idiomáticas, como quebrar um galho, até a morfologia de determinadas formações lexicais, como o par carcereiro/prisioneiro, em que, a partir de bases sinônimas, cárcere e prisão, o acréscimo do sufixo [+ eiro] cria antônimos funcionais (SALOMÃO, 2009, p. 66). Segundo Salomão (2009), três trabalhos são as marcas fundadoras no desenvolvimento da gramática das construções, o de Lakoff (1987), o de Fillmore (1988) e o de Goldberg (1995). Apesar de haver diferenças nas propostas destes diferentes pesquisadores, elas convergem nas duas premissas fundadoras da gramática de construção, sendo estas: (i) não fazem diferenciação entre léxico e gramática, em que se concebe a linguagem como rede de construções, havendo divergências somente na sua complexidade interna e (ii) o signo linguístico é uma entidade bipolar, em que há o pareamento de forma e condições de interpretação do sentido (SALOMÃO, 2009, p.69). Para os fins do presente estudo, o trabalho de Goldberg se mostra o mais pertinente e, por isso, uma breve apresentação dele será feita a seguir.

Goldberg propõe que a construção deve ser o centro dos estudos linguísticos, tornando-se sua unidade de análise, focando não apenas nas formas tidas como irregulares, mas também nas construções regulares. Para defender essa posição, Goldberg analisa, sob a ótica da construção, padrões em sentenças simples, tradicionalmente importantes na investigação linguística, a fim de comprovar o posicionamento crucial delas em uma descrição da língua. Além disso, Goldberg 
demostra a semântica associada aos padrões sentenciais (GOLDBERG, 1995, p. 14), estabelecendo a distinção entre significado construcional e significado lexical.

Em seu estudo, a autora analisa as construções de estrutura argumental e apresenta uma distinção entre papéis argumentais, relacionados à construção, e papéis participantes, relacionados aos verbos. Assim, o verbo dar ativa um frame em que outros elementos são ativados, dentre eles os papéis participantes AGENTE, PACIENTE E RECIPIENTE, correspondendo, portanto, aos papéis temáticos. Os papéis argumentais, por sua vez, são determinados pela construção, podendo ter correspondência com os papéis determinados pelo verbo ou não. Assim, numa sentença como O jogador mandou a bola para o gol (exemplos de Ferrari, 2011, p. 136), os papéis argumentais e participantes são correspondentes, uma vez que o verbo ativa três papéis participantes que se manifestam na construção (agente, paciente e meta). No entanto, numa sentença como $O$ jogador chutou a bola para o gol, o verbo requer apenas dois papéis participantes (AGENTE e PACIENTE), portanto, o papel meta (o gol) é contribuição da construção.

Assim, para haver uma construção deve haver fusão dos papéis participantes e argumentais, de acordo com dois princípios: (i) Princípio da coerência semântica, em que deve haver compatibilidade semântica entre os papéis argumentais e participantes, (ex. o participante comprador, ligado ao verbo comprar, se compatibiliza com o argumental agente); (ii) Princípio da correspondência, em que os papéis participantes têm se de fundir com os papéis argumentais, mas estes prescindem da correspondência com os primeiros (FERRARI, 2010, p. 159), conforme visto no exemplo do verbo chutar acima. Desse modo, obtém-se uma forma de análise que é mais econômica, uma vez que, ao invés de ter de se criar significações novas para itens lexicais específicos, passa-se a entender que as construções nas quais eles estão inseridos possuem carga semântica própria.

A construção é definida, portanto, como o pareamento entre forma e significado e sua "[...] inclusão na gramática se dá caso seja demonstrado que seu significado e/ou forma não sejam composicionalmente derivados de outra construção existente na língua" (GOLDBERG, 1995, p. 4) ${ }^{4}$. Dada esta definição, a autora afirma que os morfemas também são tipos de construção e, portanto, o léxico não se diferencia do restante da gramática, uma vez que são pareamentos de forma

\footnotetext{
${ }^{4}$ No original: "[...] is posited in the grammar if it can be shown that its meaning and/or form is not compositionally derived from other constructions existent in the language".
} 
e significado que não depreendem de nenhuma outra construção. A seguir, será apresentada a proposta de Booij da construção morfológica.

\subsubsection{Construções morfológicas}

Booij (2013) entende a morfologia como uma subdisciplina da linguística que investiga "as relações sistemáticas entre forma e significado de construtos linguísticos no nível da palavra" e que, portanto, a gramática de construções seria a abordagem adequada na análise morfológica por partir do pressuposto de que a "gramática é um inventário complexo de forma-significado-função em que as palavras se distinguem de construções sintáticas apenas no que diz respeito a sua complexidade interna" (MICHAELIS; LAMBRECHT apud BOOIJ, 2013, p.1) ${ }^{5}$. Dessa forma, as palavras complexas, compostas por uma base mais um sufixo ou prefixo, no português, podem ser entendidas como construções, as construções morfológicas. Estas apresentam padrões de formação de palavras que podem ser entendidos como esquemas abstratos gerais que se aplicam a conjuntos de palavras complexas existentes numa língua, mantendo relação sistemática entre forma e significado, formando um léxico hierárquico, em que os esquemas sejam o polo mais abstrato e as manifestações das palavras complexas o polo mais concreto, ou menos abstrato. Esta abordagem permite que sejam feitas generalizações sobre subclasses de palavras complexas e que se especifiquem propriedades abrangentes das construções morfológicas.

Como exemplo, o autor apresenta a construção morfológica de adjetivos deverbais ${ }^{6}$ no inglês cuja terminação se faz com o sufixo -able, tais como acceptable, afford-able, believ-able. O autor propõe que o esquema subjacente a esta construção seja como o apresentado abaixo.

(i) $[\mathrm{Vtr}-\text { able }]_{\mathrm{Adj}} \leftrightarrow$ [PODE SER SEM-ed] (Vtr = verbo transitivo, SEM = significado do constituinte relevante)

Esta notação é uma simplificação da apresentada em Booij (2013, p. 1). Nela, há a representação do polo formal da construção dos adjetivos deverbais, à esquerda e,

\footnotetext{
5 "the systematic relationships between form and meaning of linguistic constructs at the word level" "the grammar represents an inventory of form-meaning-function complexes, in which words are distinguished from grammatical constructions only with regard to their internal complexity".

${ }^{6}$ Deverbais significando que os adjetivos formados têm como base prototípica algum verbo.
} 
à direita, a representação do polo do significado. A dupla seta representa a relação no pareamento entre forma e significado.

Dessa forma, os verbos que servem de base para esses adjetivos são, prototipicamente, transitivos, e seus objetos correspondem ao argumento qualificado pelo adjetivo. Assim, o significado destes adjetivos pode ser entendido como 'algo que pode ser V-passado'. Fazendo a correspondência entre adjetivos desse tipo e seus respectivos verbos, juntamente com a regularidade da relação forma e significado, o falante da língua constrói um esquema abstrato representando a generalização presente na construção morfológica tal como o esquema, e este é parte do conhecimento que o falante possui sobre palavras desse tipo. No entanto, essa construção pode compelir a interpretação transitiva de verbos não transitivos, como pode ser observado em laughable, ou seja, a construção contribui com a transitividade que não está prevista no verbo que forma sua base. Dessa forma, esse esquema morfológico funcionaria como uma expressão idiomática construcional no nível lexical (BOOIJ, 2013, p.3), que se comporta nos moldes de uma expressão idiomática formal. Ou seja, o sufixo -able é a parte fixa da construção, e Vtr a parte variável. O autor embasa essa proposta se apoiando em evidência da realidade psicológica, que demonstra que crianças são capazes de descobrir padrões abstratos em conjuntos de palavras complexas, para atestar a produtividade dos esquemas morfológicos.

Assim, a relação entre as manifestação linguísticas que usam do sufixo -able e o esquema podem ser modeladas em um léxico hierárquico, a partir de um sistema de herança. Ou seja, manifestações individuais deste tipo de construção adjetival recebem propriedades do esquema dominante de forma predefinida, permitindo que estas manifestações possuam propriedades não especificadas pelo esquema, incorporando traços dele e, ao mesmo tempo, informações específicas de sua base de construção. Esta abordagem é útil por evitar a noção de que o léxico seja configurado por listas e regras, demonstrando como o conhecimento linguístico é uma rede de construções em que o falante adquire conhecimento abstrato a partir do contato com a língua.

\section{Apresentação e análise dos dados}

Os dados utilizados neste trabalho foram retirados do poema cidade/city/cité, de Augusto de Campos. O poema foi escrito em 1963 e teve várias publicações em 
diferentes suportes ao longo dos anos. A publicação utilizada como referência para este trabalho é a versão impressa no livro Viva Vaia (2000). O texto do poema é composto por um único neologismo que, para sua compreensão, deve ser decomposto nas palavras que o compõem. A interação dessas palavras permite a compreensão de um significado coerente. A configuração consultada é em uma única linha com as palavras estrangeiras (city e cité) abaixo. Aqui é apresentada uma adaptação do texto ${ }^{7}$ :

atrocaducapacaustiduplielastifeliferofugahistoriloqualubrimendimultiplicorganiperiodip lastipublirapareciprorustisagasimplitenaveloveravivaunivoracidade city cité

A análise do neologismo permite verificar que ele é formado por palavras compostas por diversas bases ligadas a um único sufixo -idade, formando uma grande e praticamente impronunciável palavra. As palavras formadas a partir da união entre as bases e o sufixo formam substantivos num somatório de vinte e oito, e são apresentados a seguir:

atrocidade, caducidade, capacidade, causticidade, duplicidade, elasticidade, felicidade, ferocidade, fugacidade, historicidade, loquacidade, lubricidade, mendicidade, multiplicidade, organicidade, periodicidade, plasticidade, publicidade, rapacidade, reciprocidade, rusticidade, sagacidade, tenacidade, velocidade, veracidade, vivacidade, unicidade e voracidade.

Assim, a rede de mesclagem conceptual criada no processo de interpretação do poema inicia-se a partir da identificação das palavras acima. Cada uma delas torna-se, portanto, um input na rede em que mapeamentos parciais entre esses espaços ocorrem. Esses mapeamentos são possíveis uma vez que todos os elementos compartilham de um mesmo esquema, que pode ser representado como [X-idade], em que $X$ representa a base de formação da palavra e o restante se refere ao sufixo comum a todos os elementos. O espaço genérico, conforme previsto na teoria da mesclagem conceptual, "reflete a estrutura e organização abstrata em

\footnotetext{
${ }^{7}$ Optou-se pela transcrição do texto porque a reprodução da publicação consultada, impressa em um cartão dobrável que, quando aberto, tem comprimento de 50 centímetros, tornaria a leitura impossível devido à redução necessária para colocá-la na formatação do presente artigo, além de não encontrar uma reprodução que fosse adequada para este fim.
} 
comum entre os inputs, ou seja, a estrutura compartilhada por esses domínios" (FERRARI, 2014, p.121), que, no caso, é uma construção morfológica, como será demonstrado mais adiante.

Todas as palavras extraídas do texto expressam qualidade ou característica e, de acordo com a nomenclatura tradicional, são exemplos de substantivos abstratos. Entendemos que esses substantivos têm como base de sua formação as seguintes palavras:

atroz, caduco, capaz, cáustico, duplo, elástico, feliz, feroz, fugaz, histórico, loquaz, lúbrico, mendigar, múltiplo, orgânico, periódico, plástico, público, rapace, recíproco, rústico, sagaz, tenaz, veloz, verdade, vivo, único e voraz.

Das vinte e oito palavras que servem de base para a formação dos substantivos abstratos, vinte e seis podem ser classificadas como adjetivo, conforme indicado pelo dicionário, uma é um substantivo (verdade) e uma é um verbo (mendigar). Optou-se por essa classificação das bases, pois, nas entradas apresentadas no dicionário Houaiss, não há menção a adjetivos relacionados às palavras mendicidade e veracidade, como ocorreu nos outros casos, mas ao substantivo e verbo acima citados.

A partir da análise dos dados, é possível postular a construção que representa o esquema abstrato subjacente à formação deste tipo de substantivo, os abstratos deadjetivais ${ }^{8}$ com o sufixo -idade, usando uma notação similar a de Booij:

\section{[Adj -idade] $]_{\text {substantivo abstrato }} \leftrightarrow$ [POSSUI QUALIDADE OU CARACTERÍSTICA DE SEM]}

A partir da postulação da construção de substantivos abstratos deadjetivais com o sufixo -idade, percebemos que a forma central, ou prototípica, da construção é formada a partir de um adjetivo, mas não estritamente, como os dois exemplos (verdade e mendigar) encontrados no poema demonstram, atestando sua produtividade, somada ao sufixo mencionado. Assim, manifestações individuais desse tipo de construção herdam propriedades do esquema de forma predefinida, que é a de possuir característica ou qualidade da base formadora, incorporando

\footnotetext{
8 'Deadjetivais' significa que os substantivos formados têm, como base prototípica, algum adjetivo.
} 
especificidades da base, ainda que estas não sejam previstas pelo esquema. Dessa forma, a construção aqui descrita, por refletir "a estrutura e organização abstrata em comum entre os inputs" (FERRARI, 2014, p.121), é o que se projeta no espaço genérico da rede de mesclagem conceptual.

No espaço mescla, a projeção de estruturas advindas dos inputs ocorre, conforme previsto por Fauconier e Turner, que afirmam que a "estrutura de pelo menos dois espaços mentais de input é projetada em um terceiro espaço, a 'mescla'” (2006, p. 314) 9 e, no caso, é o substantivo cidade. Isso ocorre porque Augusto de Campos seleciona somente bases para a sufixação que produzam a forma -cidade, induzindo a emergência do termo a partir da homofonia e homografia do produto da união da base mais o sufixo. Ou seja, ainda que em nenhum dos inputs ocorra o substantivo cidade, no espaço mescla ele emerge via composição. $O$ completamento traz estrutura adicional à mescla, que entendemos vir do espaço genérico, a construção dos substantivos abstratos deadjeivais. Ela autoriza a projeção de toda a semântica de cada uma das bases apresentadas nos inputs num elemento único, estruturado pelo esquema da construção aqui proposta. Desta forma, no espaço mescla, no processo de interpretação do texto, ocorre a elaboração da mesclagem, em que o substantivo emergente cidade é entendido como possuidor de todas as características e qualidades das bases formadoras dos substantivos abstratos que compõem o longo neologismo formador do texto poético analisado. Assim, o leitor pode entender que o texto informa que a cidade é atroz, caduca, capaz, cáustica, dupla, elástica, feliz, feroz, fugaz etc.

\section{Considerações finais}

Este trabalho tem como objetivo demonstrar como o referencial teórico da Linguística Cognitiva e as articulações entre conceitos desse referencial são eficazes na descrição de processos demandados na interpretação das mais variadas produções linguísticas. No presente estudo, a articulação dos conceitos de mesclagem conceptual e a proposição da gramática de construções e de construção morfológica foram utilizadas para descrever, ao menos em parte, os processos

\footnotetext{
${ }^{9}$ No original: "structure from at least two input mental spaces is projected to a third space, the "blend"'.
} 
demandados para a interpretação do poema cidade/city/cité, de Augusto de Campos.

Foi demonstrado como a decomposição do neologismo, que é o texto poético aqui analisado, em palavras que o compõem, permitiu identificar inputs em uma rede de mesclagem conceptual. As projeções entre os espaços de input dessa rede evidenciaram uma estrutura abstrata que se projeta no espaço genérico. Ao investigar no que consiste essa estrutura abstrata, foi evidenciada a probabilidade de existência de uma construção morfológica na língua portuguesa, aqui denominada de construção de substantivos abstratos deadjetivais. Esta construção é composta, prototipicamente, de um adjetivo ligado ao sufixo -idade, formando um substantivo cuja significação é possuir a qualidade ou característica do adjetivo. No entanto, existem manifestações desta construção com palavras de outras categorias, que atestam sua produtividade. Acreditamos que essa investigação corrobore a premissa da gramática de construções de que o conhecimento linguístico dos falantes de uma língua são as construções, desde estruturas sentenciais, até o nível lexical.

O estudo também corrobora a Hipótese da Invariância de Lakoff (1990), ao menos em sua formulação fraca. O pesquisador propõe que, nessa formulação, esquemas genéricos de vários tipos, não apenas imagéticos, se projetam em novos domínios sem serem alterados, estruturando-os (LAKOFF, 1990, p.72). Assim, a construção aqui proposta é um esquema não se altera em suas projeções na rede, ainda que se criem neologismos, mesmo que não dicionarizados - conforme proposto, inclusive, pelo autor do poema em entrevista televisionada (TV CULTURA DIGITAL, 2014) -, a partir de bases diversas, evidenciando a interação léxicoconceptual da linguagem.

Além disso, buscamos descrever como essa construção, junto a elementos presentes nos inputs, permitiu a criação de um espaço mescla em que emerge o substantivo cidade, sendo qualificado pela semântica das bases de formação da construção morfológica aqui descrita.

A análise dos dados corrobora a hipótese do trabalho de que, no espaço genérico da rede de mesclagem criada, a estrutura abstrata é uma construção morfológica, uma vez que as palavras formadas com o sufixo -idade no poema possuem um esquema de significação comum, mantendo, portanto, uma relação entre forma e significado constantes, definindo uma construção. Além disso, através 
da articulação dos conceitos aqui utilizados, demonstrou-se como a interpretação do texto poético demandou os "mesmos aparatos conceptuais e linguísticos que a linguagem ordinária" (LAKOFF e TURNER apud FREEMAN, 2007, p. 1185), uma vez que as proposições desses conceitos foram baseadas em observação de uso cotidiano da língua.

É importante salientar que essa construção aqui descrita é parte do conhecimento do falante da língua, ainda que não consciente, e que esse conhecimento nos permite a interpretação do texto.

O artigo, portanto, traz indícios contundentes da existência da construção de substantivos abstratos deadjetivais, além de se coadunar com as premissas fundadoras do modelo teórico da gramática de construções de que a linguagem é uma rede construcional, não havendo distinção entre léxico e gramática, e de que o signo linguístico é o pareamento forma e significado. No entanto, faz-se necessária uma investigação mais ampla das ocorrências do sufixo analisado, utilizando-se de um corpus maior, para que se possa fazer afirmações mais gerais e precisas sobre este tipo de construção na língua portuguesa. Outra pesquisa que o presente estudo abre a possibilidade é a de verificação de tal construção no inglês e francês, dado que o poema sugere que existem correspondências entre as palavras formadas no português e estas outras línguas.

\section{Referências}

BOOIJ, Geert. Construction Morphology and the Lexicon. In Selected Proceedings of the 5th Décembrettes: Morphology in Toulouse, ed. Fabio Montermini, Gilles Boyé, and Nabil Hathout, 34-44. Somerville, MA: Cascadilla Proceedings Project, 2007.

BOOIJ, Geert. Morphology in Construction Grammar. In: HOFFMANN, Thomas; TROUSDALE, Graeme (ed.). The Oxford Handbook of Construction Grammar. Oxford; New York: Oxford University Press, 2013.

CAMPOS, Augusto de. Viva Vaia. São Paulo: Atelie Editorial, 2000.

COSENZA, Henrique A. A poesia de Augusto de Campos sob a ótica da linguística cognitiva: a interpretação descrita. Dissertação (mestrado em linguística) Faculdade de Letras, Universidade Federal de Minas Gerais, 2019.

EVANS, V.; GREEN, M. Word Meaning and Radial Categories. In: EVANS, V.; GREEN, M. Cognitive Linguistics: an introduction. Edinburgh: Edinburgh University Press, 2006. 
EVANS, V.; GREEN, M. Conceptual Blending. In: EVANS, V.; GREEN, M. Cognitive Linguistics: an introduction, 400-444. Edinburgh: Edinburgh University Press, 2006.

FAUCONNIER, G. Mental Spaces. In: GEERAERTS, Dirk; CUYCKENS, Hubert (ed.). The Oxford Handbook of Cognitive Linguistics. Oxford; New York: Oxford University Press, 2007. p.400-444.

FAUCONNIER, G.; TURNER, M. Mental Spaces: conceptual integration networks In: GEERAERTS, D. (ed.). Cognitive Linguistics: basic readings. Berlin: Mouton de Gruyter, 2006. p. 303-372.

FAUCONNIER, G.; TURNER, M. The Way We Think: conceptual blending and the mind's hidden complexities. New York: Basic books, 2002.

FAUCONNIER, G. Mappings in Thought and Language. Cambridge: Cambridge University Press, 1997.

FERRARI, Lilian. Modelos de gramática em linguística cognitiva: princípios complementares. Cadernos de letras da UFF - Dossiê: Letras e cognição, n. 41, p. 149-165, 2010. Disponível em: http://www.cadernosdeletras.uff.br/joomla/images/ stories/edicoes/41/artigo7.pdf. Acesso em: 17 out. 2019.

FERRARI, Lilian. Introdução à Linguística Cognitiva. São Paulo: Contexto, 2014.

FREEMAN, H. Margaret. Cognitive Linguistic Aproaches to Literary Studies: State of the art in Cognitive Poetics. In: GEERAERTS, Dirk; CUYCKENS, Hubert (ed.).The Oxford Handbook of Cognitive Linguistics. Oxford; New York: Oxford University Press, 2007. p. 1175-1202.

GOLDBERG, Adele. Constructions: A Construction Grammar Approach to Argument Structure. Chicago: The University of Chicago Press, 1995.

LAKOFF, George. The Invariance Hypothesis. Cognitive Linguistics, vol. 1, no. 1, p. 39-74, 1990. Disponível em: https://georgelakoff.files.wordpress.com/2014/11/ invariance-hypothesis-lakoff-1990.pdf. Acesso em: 17 out. 2019.

PEZATTI, Erotilde G. A gramática da derivação sufixal: os sufixos formadores de substantivos abstratos. Alfa n. 34, p. 153-174, 1990. Disponível em: https://periodicos.fclar.unesp.br/alfa/article/view/3837/3544. Acesso em: 17 out. 2019.

SALOMÃO, Maria M. M. Gramática das construções: a questão da integração entre sintaxe e léxico. Veredas, v. 6, n. 1, p. 63-74, 2009. Disponível em: https://periodicos.ufjf.br/index.php/veredas/article/view/25296/14320. Acesso em: 17 out. 2019. 
STOCKWELL, P. Cognitive Poetics: An Introduction. London; New York: Routledge, 2002.

TV CULTURA. Cidade city cité ganha nova versão (4m10s). Disponível em: https://www.youtube.com/watch?v=POd3SueRo9U Último acesso em: 17 out. 2019.

VANDAELE, J.; BRÔNE, G. Cognitive Poetics: Goals, Gains and Gaps. Berlin: Mouton de Gruyter, 2009.

VILLAR, Mauro de Salles (dir.). Dicionário Houaiss da Língua Portuguesa. Rio de Janeiro: Objetiva, 2009. 